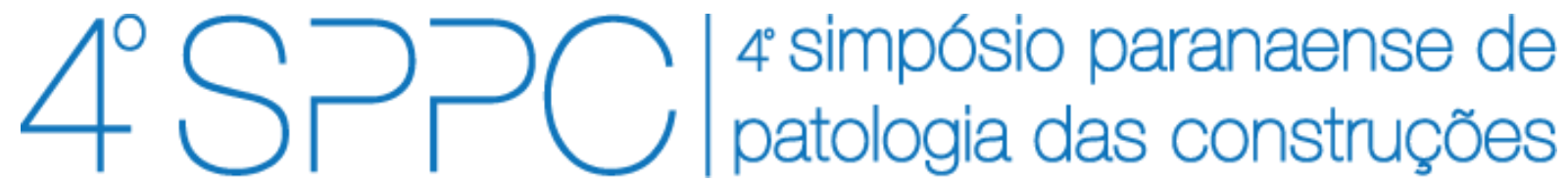

ISSN 2526-7248 artigo n. 4SPPC129, pp. 271-281, 2019

\title{
Passivação do aço carbono nas idades iniciais de hidratação do concreto armado
}

Godinho, Jayson Pereira ${ }^{1}$; Zermiani, Natalia Baggio²; Oliveira, Rafael Luiz Neves $\mathrm{de}^{3}$; Medeiros, Marcelo Henrique Farias de $^{4}$

1 Eng. Ambiental e de Segurança do Trabalho, Mestre em Ciência e Tecnologia Ambiental (PPGCTA) pela UTFPR, Doutorando em Eng. de Construção Civil (PPGECC) pela UFPR, jayson.godinho.eng@gmail.com

${ }^{2}$ Graduanda em Engenharia Civil pela Universidade Federal do Paraná (UFPR), nbz.natalia@gmail.com

${ }^{3}$ Eng. Civil, Especialista em Sistemas Estruturais em Concreto e em Gerenciamento e Execução de Obras (Instituto IDD), Mestrando em Eng. de Construção Civil (PPGECC) pela UFPR, rafaell_neves@hotmail.com

${ }^{4}$ Eng. Civil, Mestre e Doutor em Eng. Civil pela Universidade de São Paulo (USP), Docente na UFPR, Departamento de Construção Civil (DCC) e PPGECC, marcelo.ufpr@gmail.com

Resumo: O objetivo deste trabalho foi avaliar a passivação e a estabilidade eletroquímica do aço carbono nas idades iniciais de hidratação do concreto armado. Para atingir esse objetivo foram moldados 5 diferentes concretos com uma barra de aço carbono previamente limpa e imersa em solução de $\mathrm{Ca}(\mathrm{OH})_{2}$. Os resultados indicaram o aumento da resistência ôhmica e velocidade de pulso ultrassônico ao longo dos primeiros 200 dias. Por meio de parâmetros eletroquímicos de potencial de corrosão e densidade de corrente foi possível observar a passivação do aço carbono a partir dos 7 dias e ficando constante até os 200 dias mesmo com o consumo acentuado de portlandita pelas reações pozolânicas ao final do experimento.

Palavras-chave: Durabilidade, Passivação, Velocidade de corrosão.

Abstract: The objective of this work was to evaluate the passivation and electrochemical stability of carbon steel at the initial hydration ages of the reinforced concrete. To achieve this objective, 5 different concretes were molded with a carbon steel rod previously cleaned and immersed in $\mathrm{Ca}(\mathrm{OH})_{2}$ solution. The results indicated the increase of the ohmic resistance and ultrasonic pulse velocity during the first 200 days. By means of electrochemical parameters of corrosion potential and current density it was possible to observe the passivation of the carbon steel from the 7 days and being constant until the 200 days even with the accentuated consumption of portlandite by the pozzolanic reactions at the end of the experiment.

Keywords: Durability, Passivation, Corrosion Speed. 


\section{Introdução}

A corrosão do concreto armado é um dos mecanismos mais comuns de degradação de estruturas, sendo um processo espontâneo e lento, que pode ser acelerado devido a fatores externos. Mas, quando a armadura está imersa no concreto hidratado, sem o ataque de agentes agressivos, uma película protetora é formada envelopando-a. Essa película é formada pelas reações eletroquímicas que ocorrem na interface armadura/concreto, e pode ser analisada a partir do cálculo da densidade de corrente e do potencial de corrosão [1-3].

Uma das técnicas para se medir o potencial de corrosão é utilizando um voltímetro, conectado em um eletrodo de referência (geralmente cobre/sulfato de cobre) e no eletrodo de trabalho (armadura em que deseja quantificar seu potencial de corrosão) $[4,5]$. É então lida a diferença de potencial entre os dois eletrodos e assim é obtido o seu potencial de corrosão, que tem uma relação com a probabilidade de ocorrência da corrosão na armadura [3,6]. Por outro lado, a densidade de corrente, que tem correlação com a intensidade de corrosão, pode ser medida por um potenciostato. É utilizado um eletrodo a mais que no ensaio anterior, o contra-eletrodo. Assim, é aplicada uma pequena diferença de potencial (ddp) e registrada a corrente obtida nessa ddp, calculando-se, então, a resistência de polarização linear e a densidade de corrente $[7,8]$.

Um metal passivo é aquele que resiste à corrosão em soluções oxidantes fortes ou quando é aplicada uma polarização anódica. Um metal ativo-passivo tem três regiões características, quando se compara potencial e corrente registrada: região ativa, região passiva e região de transição $[9,10]$. Nas idades iniciais, a armadura está na região de transição, em que existem reações eletroquímicas com correntes anódicas, porém ao chegar a certo potencial, a corrente diminui drasticamente. Essa é a região passiva, onde se forma a película protetora. Polarizando-se mais positivamente a armadura, esta começa a sofrer corrosão na parte anódica. Essa sequência caracteriza o comportamento da armadura no concreto hidratado $[2,3,11]$.

Deste modo, o objetivo deste trabalho foi avaliar a passivação e a estabilidade eletroquímica do aço carbono nas idades iniciais de hidratação do concreto armado em cinco diferentes formulações contendo aditivos cristalizantes.

\section{Programa experimental}

\subsection{Materiais}

O cimento utilizado foi o CP V-ARI com substituição de $35 \%$ da massa total de cimento por cinza volante, para simular um cimento CP IV-32 RS, de acordo com a NBR 5737 [12]. As propriedades químicas dos aglomerantes são informadas na Tabela 1.

Tabela 1: Propriedades químicas do cimento CP V-ARI e da cinza volante.

\begin{tabular}{cccccccccc}
\hline \multirow{2}{*}{ Aglomerante } & \multicolumn{8}{c}{ Composição química (\%) } \\
\cline { 2 - 10 } & $\mathbf{C a O}$ & $\mathbf{S i O}_{2}$ & $\mathbf{A l}_{2} \mathbf{O}_{3}$ & $\mathbf{F e}_{2} \mathbf{O}_{3}$ & $\mathbf{M g O}$ & $\mathbf{S O}_{3}$ & $\mathbf{K}_{\mathbf{2}} \mathbf{O}$ & $\begin{array}{c}\text { Demais } \\
\text { Óxidos }\end{array}$ & $\begin{array}{c}\text { Perda ao } \\
\text { Fogo }\end{array}$ \\
\hline Cimento CPV-ARI & 60,61 & 18.71 & 4.26 & 2.95 & 3.52 & 3.12 & - & - & 3.34 \\
Cinza Volante & 0,29 & 54,84 & 19,88 & 5,37 & 0.59 & 0.30 & 3.00 & 1.78 & 1.26 \\
\hline
\end{tabular}


O agregado miúdo natural, oriundo da região metropolitana de Curitiba, obteve uma distribuição granulométrica dentro da zona utilizável de acordo com a NBR 7211 [13] e módulo de finura igual a 1,78 de acordo com a NBR NM 248 [14]. O agregado graúdo, também da região metropolitana de Curitiba, de origem basáltica, pode ser classificado dentro da zona granulométrica 2,36 - 9,50 mm, e possui diâmetro máximo característico (DMC) igual a $9,50 \mathrm{~mm}$. A massa específica do agregado miúdo foi de $2,30 \mathrm{~g} / \mathrm{cm}^{3}$ e do agregado graúdo foi de $2,57 \mathrm{~g} / \mathrm{cm}^{3}$.

\subsection{Moldagem dos corpos de prova}

O traço adotado foi 1: 1,9:2,47 (cimento, areia, brita) e a relação água / aglomerante 0,45 , com abatimento de $8 \pm 2 \mathrm{~cm}$, com a utilização de aditivo superplastificante à base de policarboxilato. Estes parâmetros são semelhantes aos aplicados na construção de uma Estação de Tratamento de Esgoto (ETE) na cidade de Ponta Grossa-PR. O adensamento foi realizado em mesa vibratória por 10 segundos, sendo o preenchimento dos corpos de prova feito em 1 camada de concreto de acordo com a NBR 5738 [15]. Foram moldadas cinco formulações (com base no tipo de aglomerante e adições cristalizantes), sendo elas apresentadas na Tabela 2:

Tabela 2: Formulações dos cinco diferentes concretos.

\begin{tabular}{|c|c|c|c|c|}
\hline \multicolumn{5}{|c|}{$\begin{array}{c}\text { Teor de aditivo superplastificante adicionado à mistura para atingir o } \\
\text { abatimento especificado }(\%)\end{array}$} \\
\hline V & $\mathbf{R}$ & $\mathbf{M}$ & $\mathbf{P}$ & $\mathbf{S}$ \\
\hline Cimento CP & \multicolumn{4}{|c|}{$\begin{array}{c}\text { Cimentos CP V-ARI com } 35 \% \text { de substituição de sua massa } \\
\text { total por cinza volante. }\end{array}$} \\
\hline $\begin{array}{l}\text { substituição } \\
\text { por cinza } \\
\text { volante }\end{array}$ & $\begin{array}{l}\text { (Referência) } \\
\text { Sem adição de } \\
\text { cristalizantes }\end{array}$ & $\begin{array}{l}\text { Adicionado } \\
1 \% \text { de } \\
\text { cristalizante } \\
\text { comercial } 1\end{array}$ & $\begin{array}{l}\text { Adicionado } \\
1 \% \text { de } \\
\text { cristalizante } \\
\text { comercial } 2\end{array}$ & $\begin{array}{l}\text { Adicionado } 1 \% \\
\text { de solução de } \\
\text { silicato de sódio } \\
\left(\mathrm{Na}_{2} \mathrm{SiO}_{3}\right)\end{array}$ \\
\hline $0,12 \%$ & $0,13 \%$ & $0,18 \%$ & $0,15 \%$ & $0,20 \%$ \\
\hline
\end{tabular}

\subsection{Procedimento de limpeza das barras de aço carbono}

As barras de aço carbono, com 6,3 mm de diâmetro, foram limpas previamente com uma escova de aço e água potável corrente para a retirada da ferrugem superficial e resíduos de solo provenientes do local de armazenamento. Elas foram limpas duas vezes com solução descrita pela norma ASTM G1 [16] nas seguintes proporções: $500 \mathrm{~mL}$ de ácido clorídrico P.A; 3,5 g de Hexametilenotetramina e $1000 \mathrm{~mL}$ de água destilada por cerca de 15 minutos.

Após a limpeza com a solução ácida, as barras foram enxaguadas com água destilada. Imediatamente após a limpeza, as barras ficaram imersas em uma solução de hidróxido de cálcio P.A e água destilada, até o momento da moldagem nas formas de madeira, que não demorou mais do que 20 dias. Antes da moldagem, as barras foram retiradas da solução de hidróxido de cálcio, secas com papel toalha e isoladas as pontas com fita isolante e resina epóxi por cima, deixando somente uma extensão de $7 \mathrm{~cm}$ de exposição no interior do concreto (Figura 1). 


\subsection{Procedimentos de ensaio}

Foram moldados 9 corpos de prova armados de dimensões $17 \mathrm{~cm} \times 17 \mathrm{~cm} \times 11 \mathrm{~cm}$ (Figura 1), para cada uma das 5 formulações (totalizando 45 corpos de prova). Foram realizados ensaios de potencial de corrosão e de densidade de corrente de corrosão para avaliar a estabilidade eletroquímica do aço carbono. Foram realizados ensaios de velocidade de pulso ultrassônico (VPU) para avaliar a densificação e homogeneidade do concreto e, também, ensaios de DRX para avaliar a quantidade relativa de portlandita na matriz cimentícia do concreto durante os primeiros 200 dias de cura imersa em água saturada com cal.

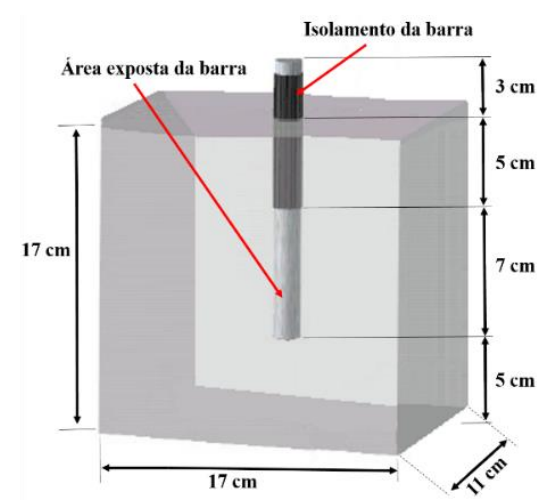

(a)

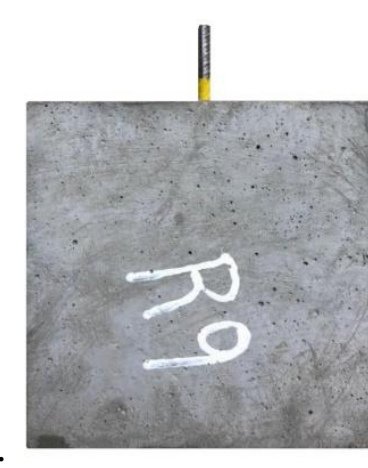

(b)

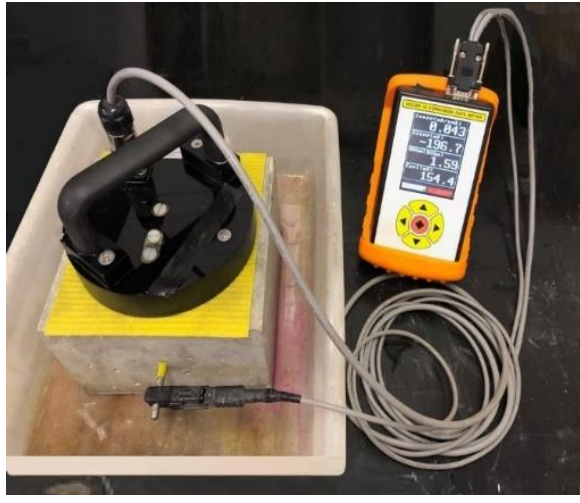

(c)

Figura 1: Corpos de prova prismáticos de concreto armado de dimensões $17 \mathrm{~cm} \mathrm{x}$ $17 \mathrm{~cm} \times 11 \mathrm{~cm}$, com barra de aço carbono de 6,3 mm de diâmetro: (a) esquema; (b) foto; (c) equipamento utilizado para os ensaios eletroquímicos.

A mensuração do potencial de corrosão $E_{c o r r}(\mathrm{mV})$, da densidade de corrente de corrosão $I_{\text {corr }}\left(\mu \mathrm{A} / \mathrm{cm}^{2}\right)$ e da resistência ôhmica foi realizado com o equipamento GECOR 10, da marca IDS S.L (Geocisa ${ }^{\circledR}$ ), em consonância com o trabalho de Capraro et al. [17] e o eletrodo de referência utilizado foi de cobre/sulfato de cobre $\mathrm{Cu} / \mathrm{CuSO}_{4}$. A resistência ôhmica foi avaliada por ser um parâmetro diretamente ligado a resistividade elétrica do material e representa a capacidade que um condutor tem de se opor à passagem de corrente elétrica. O critério de avaliação das medições de potencial de corrosão $E_{\text {corr }}$ atende ao preconizado na ASTM C876 [18], apresentado na Tabela 3.

Tabela 3: Critério de avaliação do potencial de corrosão (eletrodo de referência: cobre-sulfato de cobre - $\mathrm{Cu} / \mathrm{CuSO}_{4}$ ). Fonte: ASTM C876 [18].

\begin{tabular}{cc}
\hline $\begin{array}{c}\text { Potencial de corrosão }\left(E_{\text {corr }}\right) \text { relativo ao eletrodo } \\
\text { de referência de cobre-sulfato de cobre }(\mathbf{m V})\end{array}$ & $\begin{array}{c}\text { Probabilidade de } \\
\text { corrosão }\end{array}$ \\
\hline$<-350$ & $90 \%$ \\
-350 a -200 & Incerta \\
$>-200$ & $10 \%$ \\
\hline
\end{tabular}


Utilizou-se o critério constante no trabalho de Andrade e Alonso [8] para atrelar a densidade de corrente, $I_{\text {corr }}\left(\mu \mathrm{A} / \mathrm{cm}^{2}\right)$, ao nível de corrosão atuante na barra, conforme apresentado na Tabela 4.

Tabela 4: Critério de avaliação da densidade de corrente (eletrodo de referência: cobre-sulfato de cobre - $\mathrm{Cu} / \mathrm{CuSO}_{4}$ ). Fonte: Andrade e Alonso [8].

\begin{tabular}{cc}
\hline $\begin{array}{c}\text { Densidade de corrente }-I_{\text {corr }} \\
\left(\boldsymbol{\mu A} / \mathbf{c m}^{2}\right)\end{array}$ & Nível de corrosão \\
$<0,1$ & Desprezível \\
$0,1-0,5$ & Baixo \\
0,5 a 1,0 & Moderado \\
$>1,0$ & Alto \\
\hline
\end{tabular}

Em relação a velocidade de pulso ultrassônico VPU, as amostras de concreto foram ensaiadas conforme preconiza a norma NBR 8802 [19]. Para tal, foram utilizados um aparelho digital de ultrassom da marca Proceq, modelo Pundit Lab. e gel de ultrassonografia para o contato dos transdutores (frequência de $250 \mathrm{kHz}$ e $28 \mathrm{~mm}$ de diâmetro) com a superfície do concreto.

Quanto ao ensaio de Difratometria de Raios-X (DRX), as amostras tiveram paralisação da hidratação nas idades de 28 dias, 100 dias e 200 dias com álcool etílico absoluto 99,5\% P.A por $24 \mathrm{~h}$, levadas à estufa $(40 \pm 5){ }^{\circ} \mathrm{C}$ por mais $24 \mathrm{~h}$, e armazenadas em um dessecador contendo sílica gel até a idade das análises. As amostras de concretos paralisadas tiveram a argamassa separada da brita, de forma manual, sendo somente a argamassa finamente moídas em um moinho de panelas e analisado apenas o material passante na peneira de 325 mesh $(0,044 \mathrm{~mm})$. Posteriormente, as amostras pulverizadas foram preparadas por meio da prensagem manual e arrasamento (com o auxílio de uma lâmina de vidro) no porta-amostra de alumínio (Figura 2), que possui $9 \mathrm{~g}$ de massa, $35 \mathrm{~mm} \times 55 \mathrm{~mm}$ de dimensões e $25 \mathrm{~mm}$ de diâmetro de cavidade para a inserção da amostra $(0,4 \mathrm{~g})$ de argamassa em pó. A exposição aos raios- $X$ das amostras pulverizadas foi realizada entre $5^{\circ}$ e $75^{\circ} 2 \theta$, com passo angular de $0,02^{\circ} 2 \theta$ e tempo por passo de 1 segundo. $O$ ensaio foi realizado utilizando tubo com ânodo de cobre regulado para $40 \mathrm{kV} / 30 \mathrm{~mA}$ e fenda divergente de $1^{\circ}$, sendo a análise realizada no equipamento SHIMADZU, modelo XRD-7000 X ray diffractometer.

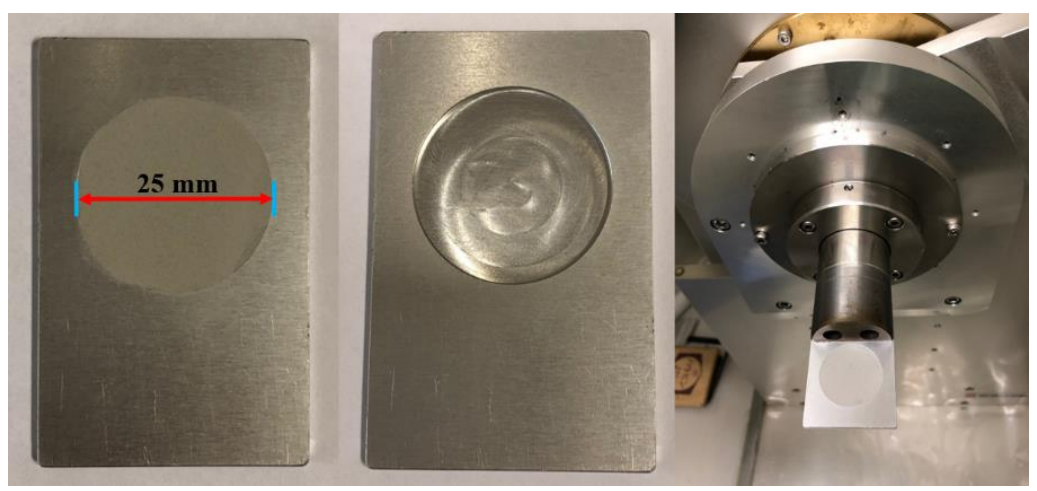

Figura 2: Porta amostra de alumínio utilizado na análise de DRX. 


\section{Resultados e discussões}

Na Figura 3 são apresentados a evolução da resistência ôhmica e da velocidade de pulso ultrassônico ao longo de 200 dias de idade do concreto.
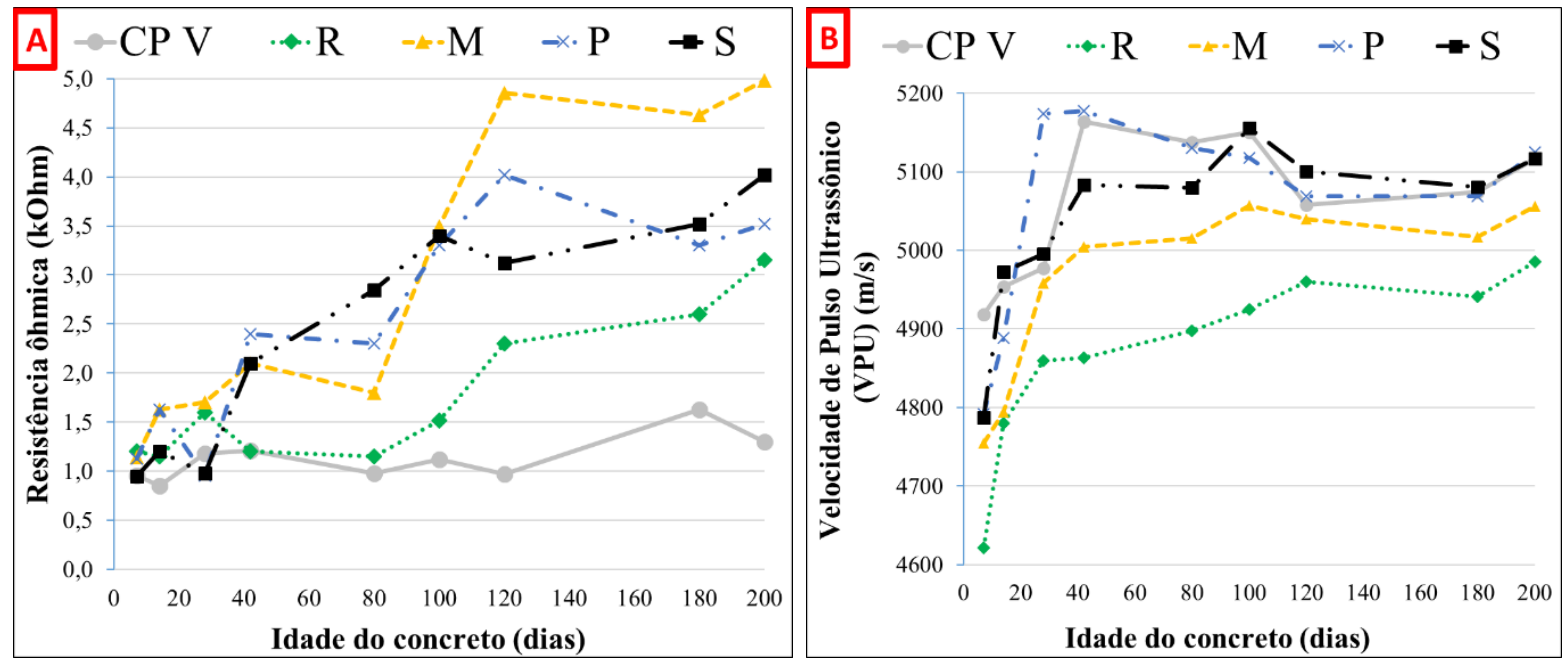

Figura 3: Avaliação indireta da densificação e homogeneidade do concreto.

A - Resistência ôhmica; B - Velocidade de pulso ultrassônico.

Legenda: CP V - somente cimento CP V, sem adição; R - Referência; M e P _ produtos comerciais; S - Solução de silicato de sódio neutro.

Na Figura 3A é possível avaliar o comportamento da resistência ôhmica, sendo que a camada percorrida pela corrente elétrica envolve o espaço de concreto entre a barra de aço (eletrodo de trabalho) e o eletrodo de referência apoiado sobre a superfície do corpo de prova. Deste modo, a resistência ôhmica tem relação direta com a hidratação do concreto. Mesmo para o CP V-ARI, cujo cimento apresenta teor diminuto de impurezas no clínquer [20], há uma tendência de elevação, ainda que sensível, na resistividade do concreto. Portanto, as reações de passivação e de corrosão do aço embutido no concreto $[2,21,22]$ tem interdependência entre a dificuldade de movimentação eletroquímica no concreto e a existência de caminhos comunicáveis pelos poros do material cimentício [20].

Nesse sentido é possível inferir que a adição de cristalizantes é benéfico às características mecânicas do concreto, pela densificação da matriz cimentícia causada pela formação no interior dos poros de produtos de cristalização. Tal constatação é corroborada pela Figura 3B, onde todos os espécimes apresentaram maior velocidade de pulso ultrassônico ao longo do tempo se comparado com a série de referência $(\mathrm{R})$. Lembrando que o $\mathrm{CP} \mathrm{V}$-ARI se caracteriza pela expressiva finura do aglomerante, o que acelera as reações iniciais do cimento principalmente nos primeiros 7 dias, é natural que o concreto com somente CP V-ARI apresente valores iniciais mais altos para a VPU em relação a todos os outros concretos. A Figura 3B demonstra que esta alta intensidade de hidratação continua até os 42 dias quando, então, permanece uma estabilização na estrutura do material. Em contrapartida, ao substituir parte do cimento por cinza volante, estas reações preliminares tendem a ocorrer de maneira mais lenta. A característica pozolânica da cinza volante presente no concreto R, indica que a VPU se estabilizou para idades superiores a 120 dias. Mas essa estabilização não foi verificada para a resistência ôhmica (Figura 3A), pois a mesma aumentou até os 200 dias de idade. 
Entre os cristalizantes, a evolução dos atributos de resistência ôhmica e velocidade de ultrassom não resultou discrepância estatística. O concreto com cristalizante M obteve uma elevação da resistência ôhmica mais intensa que os demais, mas em contrapartida, a elevação da VPU foi mais intensa para o concreto com cristalizante $P$ e também para o concreto com solução de silicato de sódio neutro (S). Na Figura 4 são apresentadas a evolução da densidade de corrente e do potencial de corrosão das barras de aço carbono.
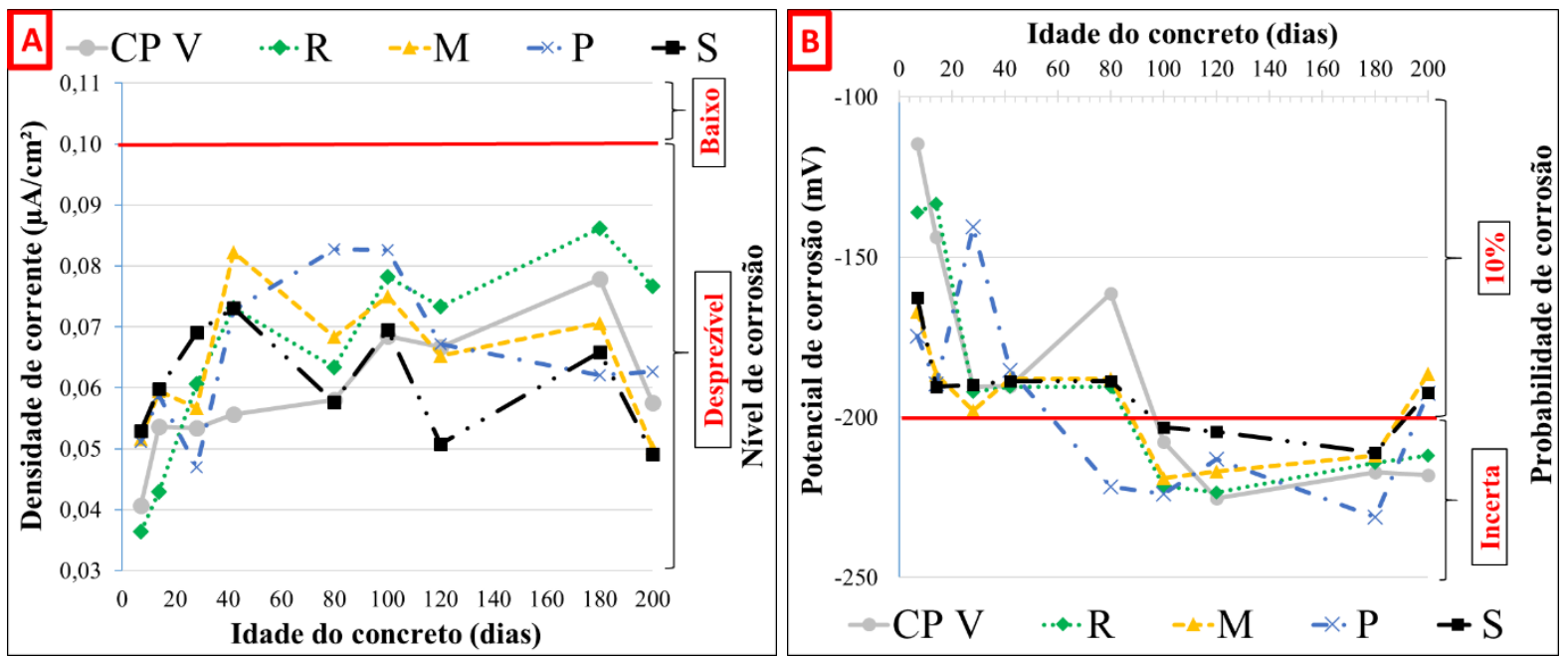

Figura 4: Ensaios eletroquímicos. A - Densidade de corrente; B - Potencial de corrosão. Legenda: CP V - somente cimento CP V, sem adição; R - Referência; M e $P$ - produtos comerciais; $S$ - Solução de silicato de sódio neutro.

É possível observar na Figura 4 que para ambos os atributos eletroquímicos, houve um período inicial de instabilidade das reações, possivelmente causada pelas reações de dissolução/precipitação inerente aos primeiros estágios da hidratação [20]. A dinâmica das concentrações iônicas e a disponibilidade de oxigênio não permitiria que os mecanismos de regulação dos processos eletroquímicos fossem relacionados apenas à permeabilidade da matriz sólida [2].

Consta na publicação de Hansson [22] que, para um ambiente de alcalinidade estável, maiores valores de potenciais estariam relacionados a menores taxas de corrosão na célula eletroquímica, conceito implícito, também, nos parâmetros adotados pela ASTM C876 [18] conforme Tabela 3, que para valores maiores que $-200 \mathrm{mV}$ a probabilidade de corrosão seria de apenas $10 \%$. Mas vale ressaltar que essa norma foi feita com ensaios experimentais para o caso de ataque do concreto armado por íons cloreto e, dessa forma, os valores podem variar para mais ou para menos, dependendo do tipo do ataque. Ainda segundo Hansson [22], em situações sem agressividade, a passivação seria regulada pela alcalinidade e pela disponibilidade de oxigênio, o qual, sendo mais espessa se tornaria a camada passivadora. Ela cita que, em elementos submersos em água, a limitação do oxigênio acaba, também, restringindo a taxa de corrosão. O oxigênio livre seria reduzido na reação reduzindo o potencial de corrosão a valores abaixo do necessário para estabilização da camada passivadora. 
$\mathrm{Na}$ Figura 4B é notado que as amostras apresentaram queda progressiva nos potenciais de corrosão até aproximadamente $-200 \mathrm{mV}$, ou seja, ultrapassando o critério de passividade da Tabela 3 atingindo a região de incerteza. No entanto, conforme os valores de densidade de corrente (Figura 4A), é possível afirmar que o concreto proporcionou condição de passividade às barras, mesmo após a tendência de intensificação do processo corrosivo nos primeiros 40 dias, os valores de densidade de corrente se estabilizaram bem abaixo do nível desprezível de corrosão estipulado na Tabela 4. Os resultados indicaram também que o procedimento de limpeza adotado para as barras foi adequado, mantendo assim a estabilidade e a passivação eletroquímica do aço carbono.

A imersão das barras em solução de hidróxido de cálcio com água destila foi essencial para que o processo de passivação das armaduras já fosse iniciado antes da moldagem dos corpos de prova. Ou seja, de acordo com a Figura 4 a armadura se verificava passivada desde as idades inicias, com critérios da Tabela 3 e Tabela 4. Sem a imersão, a curva de potencial de corrosão se iniciaria com valores mais negativos $(<-200 \mathrm{mV})$, e a curva da densidade de corrente se iniciaria com valores superiores a $0,1 \mu \mathrm{A} / \mathrm{cm}^{2}$, e com o tempo, o processo de passivação ocorria, como observado pelos autores Jiang et al. [1], Medeiros et al. [4], Rocha et al. [6], Godinho [23], Gurdián et al. [24] e Capraro et al. [17].

Na Figura 5 é apresentada a evolução do pico principal de portlandita ao longo das idades iniciais para o concreto referência $(R)$, que possui somente a substituição de $30 \%$ da massa de cimento por cinza volante.
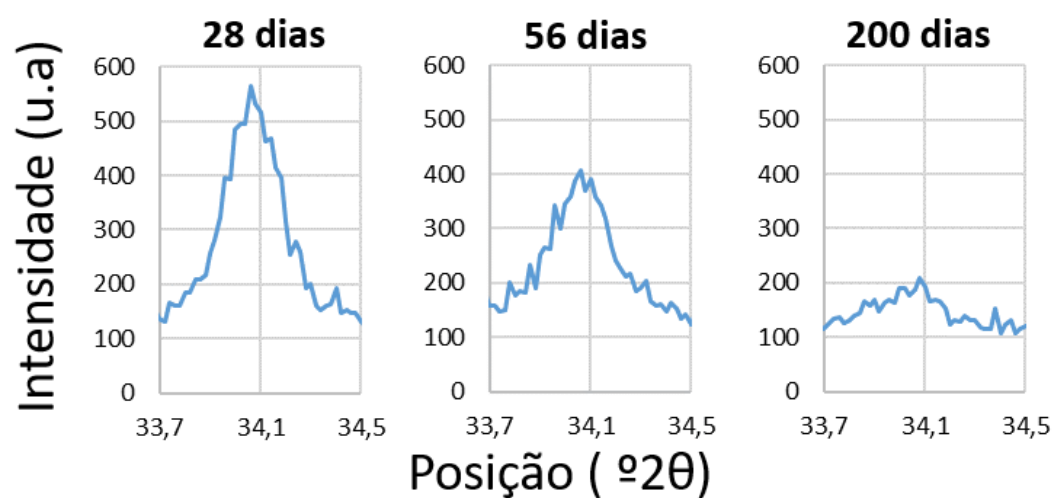

Figura 5: Intensidade do pico principal de portlandita ao longo de 200 dias de idade do concreto referência $(R)$.

Sabe-se que a portlandita é a principal responsável pela manutenção do pH elevado do concreto e consequentemente passivação do aço carbono no interior do mesmo [20]. Diante disso, foi possível notar, pela Figura 5, que durante o período de cura em água saturada com cal, parte da $\mathrm{Ca}(\mathrm{OH})_{2}$ (portlandita) foi convertida em C-S-H, em consequência das reações pozolânicas da cinza volante com o cimento, mas mesmo com esse consumo acentuado de portlandita, a estabilidade eletroquímica do aço carbono se manteve sem grandes variações, mantendo o aço carbono passivo ao longo de todo o experimento, conforme indicou os ensaios eletroquímicos. 


\section{Considerações finais}

Diante dos resultados apresentados foi possível concluir que a VPU foi influenciada pela substituição do cimento por cinza volante, sendo que o concreto referência obteve menores valores em relação ao CP V-ARI. Por outro lado, a adição de cristalizantes aumentou a VPU em relação ao concreto referência.

Em relação a resistência ôhmica a comparação entre o concreto referência e o CP VARI mostrou que a substituição do cimento por cinza volante influenciou no aumento desse parâmetro, sendo os concretos com cristalizantes com os mais altos valores. Quanto aos resultados eletroquímicos do aço carbono, foi possível concluir que o método de limpeza e a inserção das barras em hidróxido de cálcio P.A e água destilada, até o momento da moldagem, proporcionou a passivação do aço carbono nas primeiras idades e foi importante para que os valores de densidade de corrente e potencial de corrosão se mantivessem dentro da zona de passivação ao longo dos primeiros 200 dias, mesmo com o consumo acentuado de portlandita pelas reações pozolânicas.

\section{Agradecimentos}

Os autores expressam a sua gratidão as agências brasileiras CNPq, Capes e Fundação Araucária pelas bolsas e apoio financeiro, bem como à Universidade Federal do Paraná (UFPR), especificamente ao Departamento de Construção Civil (DCC), ao Programa de Pós-Graduação em Engenharia de Construção Civil (PPGECC), ao Centro de Estudos de Engenharia Civil (CESEC), ao Laboratório de Materiais e Estruturas (LAME), ao Centro de Microscopia Eletrônica (CME), ao Laboratório de Óptica de Raios X e Instrumentação (LORXI), ao grupo de pesquisa de Patologia e Recuperação das Construções (PRC) e, também, às empresas Cia. de Cimentos Itambé, Votorantim Cimentos, Buschle \& Lepper S.A, MC-Bauchemie Brasil, Penetron Brasil Ltda. e a Lubeco Ltda., pela doação de materiais para a pesquisa.

\section{Referências}

[1] Jiang, J.Y.; Wang, D.; Chu, H.Y.; Ma, H.; Liu, Y.; Gao, Y.; Shi, J.; Sun, W. (2017) The passive film growth mechanism of new corrosion-resistant steel rebar in simulated concrete pore solution: Nanometer structure and electrochemical study, Materials (Basel). 10(4):412.

[2] Poursaee A. (2016) Corrosion of Steel in Concrete Structures. Elsevier, 1st Edition. Amsterdã, Holanda.

[3] Ribeiro, D. V.; Helene, P. ; Cascudo, O. ; Tutikian, B. F. ; Sales, A. ; Souza, C. A. C. ; Cunha, M. P. T.; Lourenco, M. Z.; Almeida, F. C. R. (2018) Corrosão e Degradação em Estruturas de Concreto: Teoria, Controle e Técnicas de Análise e Intervenção, 2a , Elsevier Brasil, Rio de Janeiro-RJ.

[4] Medeiros, M. H. F.; Rocha, F. C.; Medeiros-Junior, R. A.; Helene, P. (2017) Corrosion potential: influence of moisture, water-cement ratio, chloride content and concrete cover, Revista IBRACON de Estruturas e Materiais (RIEM). 
10:864-885.

[5] Assouli, B.; Ballivy, G.; Rivard, P. (2008) Influence of environmental parameters on application of standard ASTM C876-91: half cell potential measurements, Corrosion Engineering, Science and Technology. 43:93-96.

[6] Rocha, F. C.; Campos, H. F.; Soares, T. C. C.; Roquitski, A.; Medeiros, M. H. F. (2014) Influência da espessura de cobrimento e da contaminação por cloretos nas leituras de potencial de corrosão de armaduras, Revista Eletrônica de Engenharia Civil (REEC). 8: 43-53.

[7] Broomfield, J.P. (2006) Corrosion of Steel in Concrete: Understanding, Investigation and Repair, Second Edition, $2^{\circ}$, CRC Press.

[8] Andrade, C.; Alonso, C. (2004) Test methods for on-site corrosion rate measurement of steel reinforcement in concrete by means of the polarization resistance method, Materials and Structures. 37:623-643.

[9] Sato, N., (1990) An overview on the passivity of metals, Corros. Sci. 31:1-19.

[10] Leach, J. S. L.; Pearson, B. R. (1988) Crystallization in anodic oxide films, Corrosion Science. 28:43-56.

[11] MEIRA, G.R. (2017) Corrosão de Armaduras em Estruturas de Concreto fundamentos, diagnóstico e prevenção, $1^{\text {a }}$, editora do IFPB, João Pessoa-PB.

[12] NBR 5737 (1992) Cimentos Portland resistentes a sulfatos. Associação Brasileira de Normas Técnicas - ABNT, Rio de Janeiro, Brasil.

[13] NBR 7211 (2009) Agregados para concreto - especificação. Associação Brasileira de Normas Técnicas - ABNT, Rio de Janeiro, Brasil.

[14] NM 248 (2003) Agregados - Determinação da composição granulométrica. Asociación Mercosur de Normalización - AMN. São Paulo/SP, Brasil.

[15] NBR 5738 (2016) Concreto - Procedimento para moldagem e cura de corpos de prova. Associação Brasileira de Normas Técnicas - ABNT, Rio de Janeiro, Brasil.

[16] ASTM G1 (2011) Standard Practice for Preparing , Cleaning , and Evaluating Corrosion Test. American Society For Testing And Materials - ASTM, West Conshohocken, PA, USA.

[17] Capraro, A.P.B.; Gervasio, S.; Medeiros, M.H.F.; Hoppe Filho, J.; Braganca, M.; Oliveira, I. (2016) Avaliação dos mecanismos de corrosão de concretos contaminados com diferentes teores de pirita (FeS2), in: An. do $58^{\circ}$ Congresso Brasileiro de Concreto (58 CBC 2016), Instituto Brasileiro do Concreto IBRACON, Belo Horizonte/MG, pp. 1-16.

[18] ASTM C876 (2015) Standard Test Method for Corrosion Potentials of Uncoated Reinforcing Steel in Concrete. American Society For Testing And Materials ASTM, West Conshohocken, PA, USA.

[19] NBR 8802 (2019) Concreto endurecido - Determinação da velocidade de propagação de onda ultrassônica. Associação Brasileira de Normas Técnicas ABNT, Rio de Janeiro, Brasil.

[20] Mehta, P.K.; Monteiro, P.J. (2014) Concreto: Microestrutura, Propriedades e Materiais, $2^{a}$ edição, IBRACON, São Paulo, Brasil. 
[21] LEEK, D.S. (1991) The Passivity of Steel in Concrete. Quarterly Journal of Engineering Geology. 24:55-66.

[22] Hansson, C.M. (1984) Comments on electrochemical measurements of the rate of corrosion of steel in concrete, Cement and Concrete Research. 14:574-584.

[23] Godinho, J. P.; Oliveira, R. L. N. .; Capraro, A. P. B. .; Réus, G. C. .; Medeiros, M. H. F. D. (2018) Influência das condições de limpeza de barras de aço carbono do concreto armado nas leituras eletroquímicas de densidade de corrente de corrosão e potencial de corrosão, in: $3^{\circ}$ Encontro Luso-Brasileiro de Degradação em Estruturas de Concreto (3 Degrada), São Carlos-SP. pp. 77-92.

[24] Gurdián, H.; García-Alcocel, E.; Baeza-Brotons, F.; Garcés, P.; Zornoza, E. (2014) Corrosion behavior of steel reinforcement in concrete with recycled aggregates, fly ash and spent cracking catalyst, Materials (Basel). 7:3176-3197. 